Tobias R. Andrissek

\title{
Vergeltung als Strafzweck
}

Empirisch-soziologische Begründung und kriminalpolitische Folgerungen

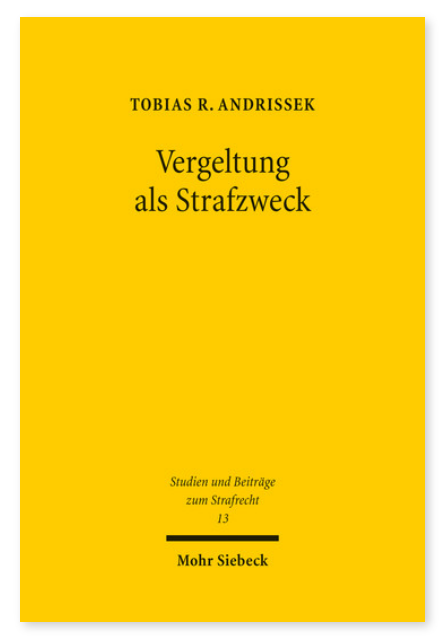

2017. XII, 258 Seiten. StudStR 13

ISBN 978-3-16-155326-4

DOI 10.1628/978-3-16-155326-4

eBook PDF 89,00€

ISBN 978-3-16-155325-7

fadengeheftete Broschur 89,00€
In der deutschen Strafzweckdiskussion wird Vergeltung heute meist als archaisch abgelehnt, ihre wenigen Befürworter argumentieren philosophisch. Tobias Andrissek begründet sie dagegen empirisch, indem er Studien aus der Evolutionsbiologie, der Verhaltenspsychologie und der Hirnforschung heranzieht.

Er kommt zu dem Ergebnis, dass es tief verwurzelte menschliche Vergeltungsbedürfnisse gibt, die der Staat befriedigen darf und muss, um für Rechtsfrieden zu sorgen und seine Autorität zu sichern. Vergeltung ist damit kein Selbstzweck, sondern Mittel zum Zweck.

Für die Kriminalpolitik ergeben sich mehrere Folgen: Der Gesetzgeber sollte die zugrundeliegenden konkreten Gerechtigkeitsintuitionen durch kriminologische Schwereforschung ermitteln, Strafhöhen sowie Strafzumessungskriterien danach ausrichten und insgesamt präziser fassen. Präventive Erwägungen sind dagegen nur zulässig, um die geeignete Art der Strafe zu bestimmen.

Tobias R. Andrissek Geboren 1988; Studium der Rechtswissenschaft an der Universität Regensburg; Rechtsreferendariat im OLG-Bezirk Nürnberg; wissenschaftlicher Mitarbeiter am Lehrstuhl für Strafrecht, Strafprozessrecht, Wirtschaftsstrafrecht und Europäisches Strafrecht an der Universität Regensburg; seit 2016 Notarassessor, derzeit in Regensburg.

Jetzt bestellen:

https://mohrsiebeck.com/buch/vergeltung-als-strafzweck-9783161553264?no_cache=1

order@mohrsiebeck.com

Telefon: +49 (0)7071-923-17

Telefax: $+49(0) 7071-51104$ 